\title{
Hematological predictors of novel Coronavirus infection
}

\author{
Gulali Aktas ${ }^{1 *}$ (1)
}

Dear Editor,

I read the article titled Can the neutrophil/lymphocyte ratio (NLR) have a role in the diagnosis of coronavirus 2019 disease (COVID-19)? by Nalbant et al. ${ }^{1}$, which was published in your journal's May 2020 issue. Neutrophil/lymphocyte ratio (NLR), Platelet/lymphocyte ratio (PLR), and c-reactive protein (CRP), three important inflammatory markers, were found to be higher in Covid-19 positive patients than Covid-19 negative subjects ${ }^{1}$. CRP is a universal inflammatory marker and increases in many infectious and inflammatory conditions. Despite that the correlation between NLR and CRP or PLR and CRP was not evaluated in the study, the authors found that an NLR level greater than $2.4 \%$ has an odds ratio of 20.3 for positive Covid-19 test result ${ }^{1}$.

Hemogram indexes are considered novel inflammatory markers in many recent studies in the literature. Of these, elevated NLR is suggested as a predictor of poor outcome in patients with Covid-19 infection ${ }^{2,3}$. Covid-19 patients with high NLR levels were reported to have increased interleukin-6 and tumor necrosis factor-alpha and appeared to recover more difficultly than those with lower NLR levels ${ }^{4}$.

Mean platelet volume (MPV) is another inflammatory marker derived from the hemogram test. Despite MPV values of Covid-19 positive and negative subjects were not statistically different in Nalbant et al.'s study ${ }^{1}$, it was suggested as a useful tool in the prediction of the Covid-19 infection in diabetic subjects 5 .

The PLR was also studied in Covid-19 disease in the literature. Authors showed that high PLR levels indicate poorer prognosis and longer hospital stay in covid-19 positive patients ${ }^{6}$. In addition, patients with severe Covid-19 infection have greater PLR levels than those of non-severe Covid-19 infection ${ }^{2}$. According to the data in the literature, not only NLR but also PLR was introduced as an independent prognostic marker of disease severity in patients with Covid-19 infection ${ }^{7}$.

Other hemogram indices studied in Covid-19 infection are red cell distribution width (RDW) and monocyte to lymphocyte ratio (MLR). Elevated RDW levels in patients with Covid-19 infection were reported compared to the healthy control subjects ${ }^{8}$. Moreover, it has been reported that increased MLR in patients with Covid-19 infection compared to healthy controls? .

In conclusion, both NLR, MPV, PLR, RDW, and MLR are useful tools in the prediction of the disease, its severity, and the mortality of Covid-19 infection. Cost-effective and easyto-assess nature of these tests may contribute to their utility in clinical practice.

\footnotetext{
'Bolu Abant Izzet Baysal University, Department of Internal Medicine - Bolu, Turkey.

*Corresponding author: draliaktas@yahoo.com

Conflicts of interest: the authors declare there are no conflicts of interest. Funding: none.

Received on August 12, 2020. Accepted on September 20, 2020.
} 


\section{REFERENCES}

1. Nalbant A, Kaya T, Varim C, Yaylaci S, Tamer A, Cinemre H. Can the neutrophil/lymphocyte ratio (NLR) have a role in the diagnosis of coronavirus 2019 disease (COVID-19)? Rev Assoc Med Bras (1992). 2020;66(6):746-51. https://doi.org/10.1590/1806-9282.66.6.746

2. Yang AP, Liu JP, Tao WQ, Li HM. The diagnostic and predictive role of NLR, d-NLR and PLR in COVID-19 patients. Int Immunopharmacol. 2020;84:106504. https://doi.org/10.1016/j.intimp.2020.106504

3. Liu Y, Du X, Chen J, Jin Y, Peng L, Wang HHX, et al. Neutrophilto-lymphocyte ratio as an independent risk factor for mortality in hospitalized patients with COVID-19. J Infect. 2020;81(1):e612. https://doi.org/10.1016/j.jinf.2020.04.002

4. Zhang B, Zhou X, Qiu Y, Song Y, Feng F, Feng J, et al. Clinical characteristics of 82 cases of death from COVID-19. PLoS One. 2020;15(7):e0235458. https://doi.org/10.1371/journal.pone.0235458

5. Ozder A. A novel indicator predicts 2019 novel coronavirus infection in subjects with diabetes. Diabetes Res Clin Pract. 2020;166:108294. https://doi.org/10.1016/J.diabres.2020.108294
6. Qu R, Ling Y, Zhang YH, Wei LY, Chen X, Li XM, et al. Plateletto-lymphocyte ratio is associated with prognosis in patients with coronavirus disease-19. J Med Virol. 2020;92(9):1533-41. https://doi.org/10.1002/jmv.25767

7. Chan AS, Rout A. Use of neutrophil-to-lymphocyte and platelet-to-lymphocyte ratios in COVID-19. J Clin Med Res. 2020;12(7):448-53. https://doi.org/10.14740/ jocmr4240

8. Sharma D, Dayama A, Banerjee S, Bhandhari S, Chatterjee A, Chatterjee D. To study the role of absolute lymphocyte count and RDW in COVID 19 patients and their association with appearance of symptoms and severity. J Assoc Physicians India. 2020;68(8):39-42. PMID: 32738839

9. Sun $\mathrm{S}, \mathrm{Cai} X$, Wang $\mathrm{H}, \mathrm{He} \mathrm{G}$, Lin $\mathrm{Y}$, Lu B, et al. Abnormalities of peripheral blood system in patients with COVID-19 in Wenzhou, China. Clin Chim Acta. 2020;507:174-80. https:// doi.org/10.1016/j.cca.2020.04.024 